\title{
Effects of Dopamine in Man: Augmentation of Sodium Excretion, Glomerular Filtration Rate, and Renal Plasma Flow*
}

\author{
Robert H. McDonald, JR., † Leon I. Goldberg, $\$$ John L. McNay,§ and \\ Elbert P. Tuttle, Jr. \\ (From the Department of Medicine and the Department of Pharmacology, Emory University, \\ Atlanta, Ga.)
}

Dopamine (3,4-dihydroxyphenylethylamine) is considered to be the immediate metabolic precursor of norepinephrine (1), from which it differs by the absence of a $\beta-\mathrm{OH}$ group. Despite this chemical similarity, previous studies of the action of dopamine (2-9) have demonstrated that many of the circulatory and metabolic effects of this catecholamine are different from those produced by norepinephrine. Horwitz, Fox, and Goldberg (6) observed that intravenous administration of dopamine to normal subjects produced consistent increases in cardiac output and either decreased or did not change peripheral resistance. Norepinephrine, on the other hand, decreases or does not change cardiac output and increases peripheral resistance in normal subjects (10). The circulatory effects of dopamine are potentiated by monoamine oxidase inhibitors to a much greater extent than are those of norepinephrine (9). Dopamine also contrasts with norepinephrine in its failure to increase circulating free fatty acids ( 7 , $8)$. These differences suggest that the effects of

* Submitted for publication July 12, 1963; accepted January 30, 1964.

Presented in part at the National Meeting of the American Federation for Clinical Research, April 28, 1963. Supported by U. S. Public Health Service grants H-6491, HE-04191-03, and $8 \mathrm{MO} 1-\mathrm{FR}-39-03$ and grants from the American and Georgia Heart Associations and the Heart Association of Palm Beach and Martin Counties (Fla.). This paper is contribution No. 624, Division of Basic Health Sciences.

† Clinical pharmacology trainee supported by U. S. Public Health Service grant 5 TI HE 5582-03. Present address: National Heart Institute, Bethesda, Md.

$\ddagger$ Recipient, Burroughs Wellcome Fund clinical pharmacology award.

$\S$ Postdoctoral fellow of the National Heart Institute, U. S. Public Health Service.

|| Holder, Georgia Heart Association Chair of Cardiovascular Research. dopamine do not depend entirely upon conversion to norepinephrine.

Recently, Goldberg, McDonald, and Zimmerman (11) reported that sodium excretion was markedly increased after administration of dopamine to four patients with congestive heart failure. Since similar increases in sodium excretion have not been reported after administration of other sympathomimetic amines, it seemed desirable to define the specific properties of dopamine responsible for this action. The present investigation was designed to determine the effects of dopamine on the renal clearances of inulin and paraaminohippurate and on electrolyte and total solute excretion in normal subjects and in patients with congestive heart failure. Cardiac output was also measured in normal subjects to determine whether dopamine altered the fraction of the cardiac output perfusing the kidneys.

\section{Methods}

Normal subjects. All subjects were male and with the exception of $\mathrm{M}$. Br., a graduate student, the volunteers were studied at the U. S. Federal Penitentiary, Atlanta, Ga. Ages ranged from 23 to 36 years with a mean age of 34 years. A common protocol with slight modifications was followed in each study. The volunteer was admitted to the ward on which the studies were being conducted. Laboratory tests, electrocardiogram, medical history, and physical examination were obtained on each subject. No subject had clinical evidence of cardiovascular or renal disease.

Dopamine $^{1}$ was administered intravenously as a dilute solution in 5\% dextrose in water. The rate of infusion was controlled by a Harvard peristaltic infusion pump (model 600-1200). The dose of dopamine to be used was determined 2 days before the renal and cardiovascular studies by trial infusion. The dose to be used

$13-\mathrm{OH}$ tyramine, grade A, California Corporation for Biochemical Research, Los Angeles, Calif. 
in the studies was the largest that could be infused without increasing mean arterial blood pressure. In a few subjects the dose so determined produced slight change in arterial pressure during the subsequent studies.

The subject was served the routine hospital diet, and no attempts were made to achieve electrolyte balance. Two days after admission renal clearance and electrolyte excretion studies were carried out in the morning in the postabsorptive state. At the start of the procedure the subjects were given 15 to $20 \mathrm{ml}$ per $\mathrm{kg}$ of water by mouth, and an indwelling catheter was placed in the bladder (except in M. B., who was allowed to void spontaneously). No attempt was made to maintain a state of constant hydration in the subjects, except in subjects $\mathrm{M}$. $\mathrm{Br}$. and $\mathrm{R}$. J., who were offered water at a rate equal to urine output. A 20-gauge Riley needle was placed in an arm vein for blood sampling except in the subjects in whom cardiac output studies were to be performed. In the latter cases, samples for both dye curves and renal clearance studies were obtained through an 18 gauge Cournand needle in the brachial artery. After priming doses of inulin and sodium para-aminohippurate (PAH) were administered and sustaining infusions were begun, a 40-minute period was allowed for equilibration. Three control urine samples at intervals of approximately 20 minutes each were then collected. Blood samples were obtained between 4 and 6 minutes after the beginning of each collection period. At the conclusion of each period, the bladder was emptied by suprapubic pressure and then re-emptied after the introduction of $50 \mathrm{ml}$ of air. When urine flow was below $6 \mathrm{ml}$ per minute, the bladder was washed with $20 \mathrm{ml}$ of sterile distilled water.

At the conclusion of the three control periods, duplicate cardiac output determinations were obtained in five of the normal subjects by injection of indocyanine green intravenously through an indwelling catheter that had been advanced to the axillary level. After this, dopamine was infused at the rate determined previously.
A second period of at least 40 minutes was allowed for equilibration. Cardiac output determinations, in duplicate, were repeated. Immediately thereafter, three more 20-minute renal clearance studies were performed.

Blood pressure was recorded continuously by a strain gauge manometer throughout the study in cases where an arterial needle was in place. Otherwise, the blood pressure was obtained by auscultation every 5 minutes. Lead II electrocardiograms were monitored continuously on an oscilloscope. Mean blood pressure was calculated as the diastolic pressure plus one-third the pulse pressure. Peripheral resistance has been expressed in terms of a peripheral resistance index ( $P R I=$ mean blood pressure/cardiac index). A minimum of two calibration points was determined for each set of dye curves.

Patients with congestive heart failure. Six patients with marked sodium retention attributed to cardiac insufficiency were studied. The presence of cardiac failure was established by history, physical examination, and radiologic studies. The age, sex, and diagnosis of the patients are shown in Table III. No single index of the degree of fluid retention is applicable to all members of the group. The response to restricted sodium intake indicated that F. R., J. B., and E. B. had a marked tendency to gain weight unless sodium intake was restricted to less than $1 \mathrm{~g}$ per day. Patients C. S. and P. W. were felt to be retaining sodium as judged by the presence of the edema and weight loss after diuretic therapy. The remaining patients, M. B., had roentgenographic evidence of pulmonary vascular engorgement and pleural effusions. All patients had grade III to IV heart disease by American Heart Association criteria.

Protocol. Patient C. S. was studied at Grady Memorial Hospital, and all other patients were investigated at the Clinical Research Facility of Emory University Hospital. The diet of the patients contained 500 or 1,000 $\mathrm{mg}$ of sodium. The patients were ambulatory, and water

TABLE I

Renal effects of dopamine infusions in normal subjects*

\begin{tabular}{|c|c|c|c|c|c|c|c|c|c|c|c|c|c|}
\hline \multirow[t]{3}{*}{ Subject } & \multirow{3}{*}{$\begin{array}{c}\begin{array}{c}\text { Dopamine } \\
\text { infusion } \\
\text { rate }\end{array} \\
\mu g / \mathrm{kg} / \min \end{array}$} & \multicolumn{2}{|c|}{$\mathrm{C}_{\mathrm{In}}$} & \multicolumn{2}{|c|}{$\mathrm{C}_{\text {PAH }}$} & \multicolumn{2}{|c|}{$\mathrm{C}_{\text {osm }}$} & \multicolumn{2}{|c|}{$\mathrm{UNaV}_{\mathrm{Na}}$} & \multicolumn{2}{|c|}{$\mathrm{UKV}_{\mathbf{K}}$} & \multicolumn{2}{|c|}{$\begin{array}{l}\text { Urine } \\
\text { flow }\end{array}$} \\
\hline & & \multicolumn{2}{|c|}{$m l / m i n$} & \multicolumn{2}{|c|}{$\mathrm{ml} / \mathrm{min}$} & \multicolumn{2}{|c|}{$m O s m / m i n$} & \multicolumn{2}{|c|}{$\mu E q / \min$} & \multicolumn{2}{|c|}{$\mu E q / \min$} & \multicolumn{2}{|c|}{$m l / m i n$} \\
\hline & & c & $\mathrm{e}$ & c & e & c & e & c & e & c & e & c & e \\
\hline V.P. & 4.7 & 130 & 141 & 693 & 876 & 4.98 & 8.09 & 170 & 743 & 203 & 172 & 16.30 & 10.87 \\
\hline M. Br. & 4.3 & 100 & 118 & 402 & 847 & 3.80 & 6.91 & 281 & 699 & 41 & 49 & 8.85 & 14.19 \\
\hline P. C. & 3.8 & 100 & 105 & 463 & 739 & 3.71 & 4.91 & 174 & 550 & 92 & 74 & 14.92 & 10.51 \\
\hline B. $\mathbf{K}$. & 5.2 & 87 & 106 & 452 & 663 & 2.93 & 5.29 & 187 & 522 & 63 & 71 & 9.50 & 6.89 \\
\hline R. J. & 4.3 & 119 & 121 & 528 & 788 & 2.58 & 4.93 & 93 & 413 & 51 & 58 & 9.43 & 20.12 \\
\hline H. S. & 3.8 & 113 & 120 & 482 & 593 & 3.10 & 7.42 & 142 & 701 & 41 & 74 & 7.34 & 7.13 \\
\hline C. W. & 4.2 & 105 & 154 & 431 & 784 & 2.09 & 7.78 & 61 & 784 & 73 & 95 & 5.26 & 5.44 \\
\hline R. S. & 7.1 & 117 & 151 & 541 & 808 & 4.28 & 4.98 & 245 & 435 & 94 & 124 & 17.50 & 4.26 \\
\hline J. S. & 2.6 & 110 & 118 & 571 & 1,093 & 2.83 & 4.03 & 176 & 361 & 51 & 71 & 13.94 & 9.34 \\
\hline Average & & 109 & 126 & 507 & 798 & 3.36 & 6.03 & 171 & 575 & 79 & 87 & 11.44 & 9.86 \\
\hline $\mathrm{CV}$ & & & $9.4 \%$ & 11. & 9. & & & & 9 & & & & \\
\hline p & & \multicolumn{2}{|c|}{$<0.02$} & \multicolumn{2}{|c|}{$<0.01$} & \multicolumn{2}{|c|}{$<0.01$} & \multicolumn{2}{|c|}{$<0.01$} & \multicolumn{2}{|c|}{ NS } & \multicolumn{2}{|c|}{ NS } \\
\hline
\end{tabular}

* All values are corrected to $1.73 \mathrm{~m}^{2} \mathrm{BSA}$ and represent the average of three clearance periods. Abbreviations: $\mathrm{C}_{\mathrm{In}}=$ inulin clearance; $\mathrm{CPAH}_{\mathrm{PA}}=$ para-aminohippurate $(\mathrm{PAH})$ clearance; $\mathrm{C}_{\mathrm{OsIn}}=$ osmolal clearance; $\mathrm{UNaV}_{\mathrm{Na}}=$ urinary sodium excretion; UKV $=$ urinary potassium excretion; $\mathrm{c}=$ control periods: $\mathrm{e}=$ experimental periods, $\mathrm{CV}=$ coefficient of variation. See methods for statistical techniques. 
TABLE II

Cardiovascular effects of dopamine infusions in normal subjects

\begin{tabular}{|c|c|c|c|c|c|c|c|c|c|c|c|c|c|c|c|c|c|}
\hline \multirow[t]{3}{*}{ Subject } & \multirow{3}{*}{$\frac{\begin{array}{c}\text { Dopamine } \\
\text { infusion } \\
\text { rate }\end{array}}{\mu g / \mathrm{kg} / \min }$} & \multicolumn{2}{|c|}{$\begin{array}{l}\text { Mean blood } \\
\text { pressure }\end{array}$} & \multicolumn{2}{|c|}{$\begin{array}{c}\text { Pulse } \\
\text { pressure }\end{array}$} & \multicolumn{2}{|c|}{$\begin{array}{l}\text { Heart } \\
\text { rate }\end{array}$} & \multicolumn{2}{|c|}{$\begin{array}{l}\text { Renal blood } \\
\text { flow index* }\end{array}$} & \multicolumn{2}{|c|}{$\underset{\text { index }}{\text { Cardiac }}$} & \multicolumn{2}{|c|}{$\begin{array}{l}\text { Stroke } \\
\text { indext }\end{array}$} & \multicolumn{2}{|c|}{$\begin{array}{l}\text { Peripheral } \\
\text { resistance } \\
\text { index } \neq\end{array}$} & \multicolumn{2}{|c|}{$\underset{\text { fraction§ }}{\text { Renal }}$} \\
\hline & & \multicolumn{2}{|c|}{$m m H g$} & \multicolumn{2}{|c|}{$m m \mathrm{Hg}$} & \multicolumn{2}{|c|}{$\begin{array}{l}\text { beats/ } \\
\text { min }\end{array}$} & \multicolumn{2}{|c|}{$\mathrm{ml} / \mathrm{min} / \mathrm{m}^{2}$} & \multicolumn{2}{|c|}{$L / \min / m^{2}$} & \multirow[b]{2}{*}{ c } & \multirow[b]{2}{*}{ e } & \multirow[b]{2}{*}{ c } & \multirow[b]{2}{*}{ e } & \multicolumn{2}{|c|}{$\%$} \\
\hline & & c & e & c & e & $\mathrm{c}$ & e & c & $\mathbf{e}$ & c & e & & & & & c & e \\
\hline V.P. & 4.7 & 97 & 106 & 35 & 80 & 61 & 73 & 741 & 938 & & & & & & & & \\
\hline M. Br. & 4.3 & 89 & 92 & 49 & 75 & 49 & 49 & 415 & 870 & & & & & & & & \\
\hline P. C. & 3.8 & 103 & 107 & 44 & 70 & 70 & 75 & 496 & 791 & & & & & & & & \\
\hline B. $\mathbf{K}$. & 5.2 & 96 & 105 & 36 & 66 & 76 & 77 & 475 & 697 & & & & & & & & \\
\hline R. J. & 4.3 & 88 & 83 & 39 & 58 & 75 & 67 & 576 & 856 & 2.47 & 3.59 & 33 & 51 & 36 & 24 & 23 & 24 \\
\hline H. S. & 3.8 & 117 & 116 & 57 & 68 & 72 & 68 & 497 & 612 & 2.92 & 4.48 & 42 & 59 & 40 & 25 & 17 & 14 \\
\hline C. W. & 4.2 & 107 & 112 & 69 & 100 & 64 & 78 & 479 & 875 & 3.21 & 5.25 & 54 & 67 & 34 & 22 & 14 & 17 \\
\hline R. S. & 7.1 & 94 & 91 & 50 & 75 & 65 & 79 & 517 & 772 & 3.09 & 4.29 & 45 & 51 & 31 & 22 & 17 & 18 \\
\hline J. S. & 2.6 & 83 & 78 & 39 & 44 & 66 & 81 & 580 & 1108 & 3.36 & 4.66 & 43 & 57 & 25 & 16 & 17 & 24 \\
\hline \multirow[t]{2}{*}{ Mean } & & 97 & 99 & 46 & 71 & 66 & 73 & 531 & 835 & 3.01 & 4.45 & & 57 & 33 & 22 & 17.6 & 19.4 \\
\hline & & \multicolumn{2}{|c|}{ NS } & \multicolumn{2}{|c|}{$<0.01$} & \multicolumn{2}{|c|}{ NS } & \multicolumn{2}{|c|}{$<0.01$} & \multicolumn{2}{|c|}{$<0.01$} & \multicolumn{2}{|c|}{$<0.01$} & \multicolumn{2}{|c|}{$<0.01$} & \multicolumn{2}{|c|}{ NS } \\
\hline
\end{tabular}

* Effective renal plasma flow/1-hematocrit.

$\dagger$ Cardiac index/heart rate.

Mean blood pressure/cardiac index.

was not restricted. All drugs were discontinued except for maintenance doses of digoxin and anticoagulants. The dose of dopamine to be infused was determined several days before study by the same technic as employed with the normal subjects. Bladder catheterization was used for obtaining urine specimens except in patients T. R. and E. B. A 40-minute period was allowed for washout of urinary dead space after dopamine infusion was started. The protocol differed from that used in the normal subjects in the following ways: 1) Excess water was not given before the study. 2) Cardiac output determinations were not made. 3) All blood pressure measurements were obtained with a sphygmomanometer.
Analytical techniques. Inulin was analyzed by a modification of the method of Roe, Epstein, and Goldstein (12), and PAH by the method of Smith and associates (13). Sodium and potassium were analyzed on a flame photometer with an internal lithium standard. Osmolality was determined by measurement of freezing point with a Fiske osmometer. Duplicate analyses were made on separate samples of specimens. Cardiac output measurements were determined with a Waters $(\times 300)$ densitometer, and the curves were calibrated by a previously described volumetric technique (14). Calculations were made according to the Stewart-Hamilton formula (15).

Preparation of dopamine. Dopamine was prepared in sterile ampules after passage through a $0.40-\mu$ Millipore

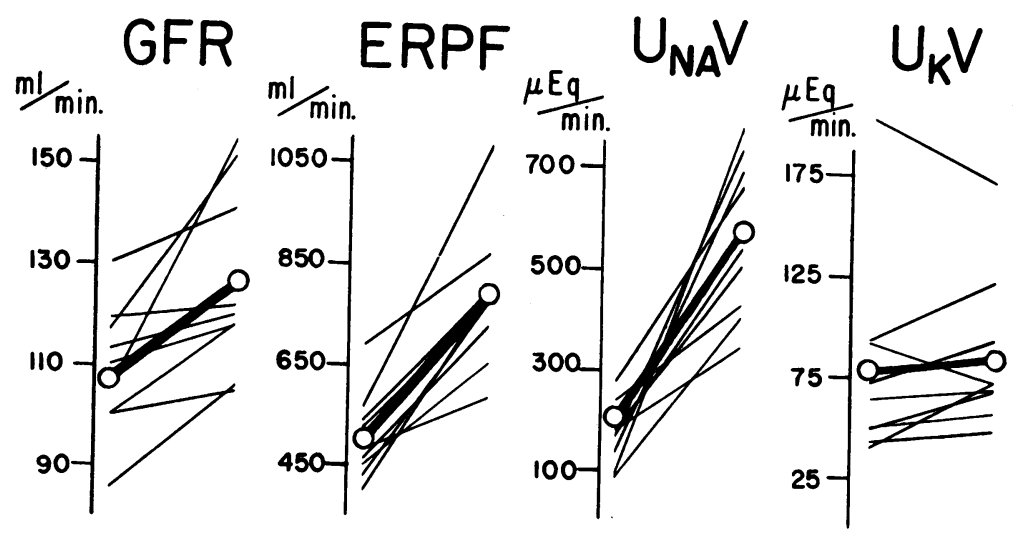

Fig. 1. Effects of intravenous infusions of Dopamine on gLOMERULAR Filtration RATE (GFR), ESTIMATEd RENAL PLASMa FLOW (ERPF), SODIUM EXCRETION ( $U_{\mathrm{Na}} V$ ), AND POTASSIUM EXCRETION ( $U_{\mathrm{K} V}$ ) IN NINE NORMAL SUBJECTS. The starting point of each line designates the average of three control determinations, and the final point signifies the average of three determinations during dopamine infusion. The heavy line is the average for the nine subjects. All values are corrected to $1.73 \mathrm{~m}^{2}$ BSA. 
filter. Sodium metabisulfite, $0.2 \%$, was added as a preservative.

Statistical methods. The data from the normal subjects were homogeneous in variance, permitting analysis by the paired $t$ test (16). This test, however, was unsuitable for the response of the patients in congestive heart failure because of the wide variability of response. In the latter group the presence of two subjects showing large responses suggests a skewness to the right. The high values of the positive responses of these patients increased the means and variances for the group, and the variance of the data varied with the magnitude of the mean. For these data the $t$ test was applied more appropriately to the logarithms of the ratio: observation during dopamine infusion/ observation before dopamine infusion (17).

The coefficient of variation (CV) (18) was calculated as $100 \times$ square root of the within-subject mean square for a given experimental condition divided by the mean for the experimental condition. This indicates the relative variability of the clearance and excretion data. $\mathrm{By}$ comparison, our calculations of $\mathrm{CV}$ from the statistical data of Davies and Shock (19) yielded values of $7.0 \%$ for inulin clearance and $6.3 \%$ for Diodrast clearance.

\section{Results}

Effects of dopamine infusions in normal subjects. The renal clearance and electrolyte excretion data are shown in Table I and graphically presented in Figure 1. Typical effects in one subject are shown in Figure 2. Glomerular filtration rate (GFR), effective renal plasma flow (ERPF), sodium excretion $\left(\mathrm{U}_{\mathrm{Na}} \mathrm{V}\right)$, and osmolar clearance $\left(\mathrm{C}_{\text {osm }}\right)$ increased in each case studied and significantly in the group as a whole. Changes in potassium excretion $\left(\mathrm{U}_{\mathrm{K}} \mathrm{V}\right)$ and urine flow were variable. Free water clearance decreased in each patient except M. B. and R. J. There was no significant change in serum sodium

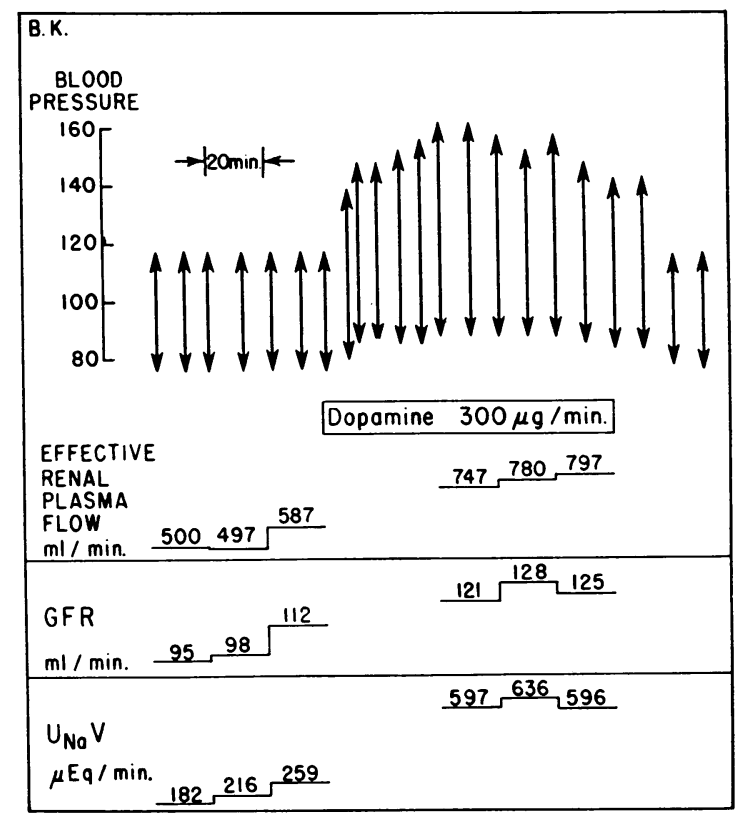

Fig. 2. EfFECtS OF DOPAMine on ARTERIAL blOOD PRESSURE, EFFECTIVE RENAL PLASMA FLOW, GLOMERULAR FILTRATION RATE (GFR), AND SODIUM EXCRETION ( $\mathrm{U}_{\mathrm{Na}_{\mathrm{a}} \mathrm{V}}$ ) IN NORMAL SUBJECT B. $\mathrm{K}$.

concentration, and changes in filtered load of sodium were proportional to changes in GFR.

The cardiovascular data are summarized in Table II and Figure 3. In the five subjects in whom cardiac output determinations were obtained, the cardiac index increased an average of $1.44 \mathrm{~L}$ per minute. Pulse pressure increased in each subject, but mean blood pressure was not significantly changed. The peripheral resistance index decreased in each subject. The renal fraction of the cardiac index did not change significantly.

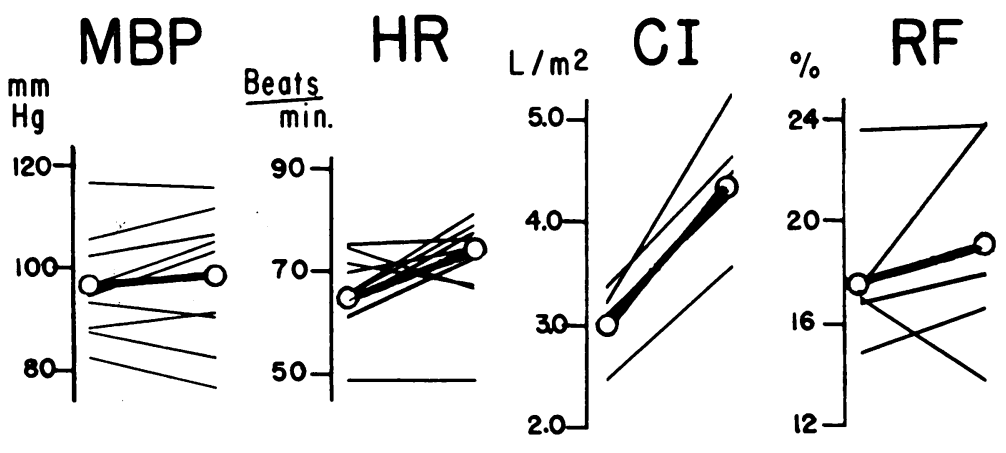

Fig. 3. EFFeCts of INTRAVENOUS INFUSIONS OF DOPAMINE ON MEAN ARTERIAL bLOOD PRESSURE (MBP), heART RATE (HR), CARDiaC INDEX (CI), AND RENAL FRACTION (RF) IN NORMAL SUBJECTS. 


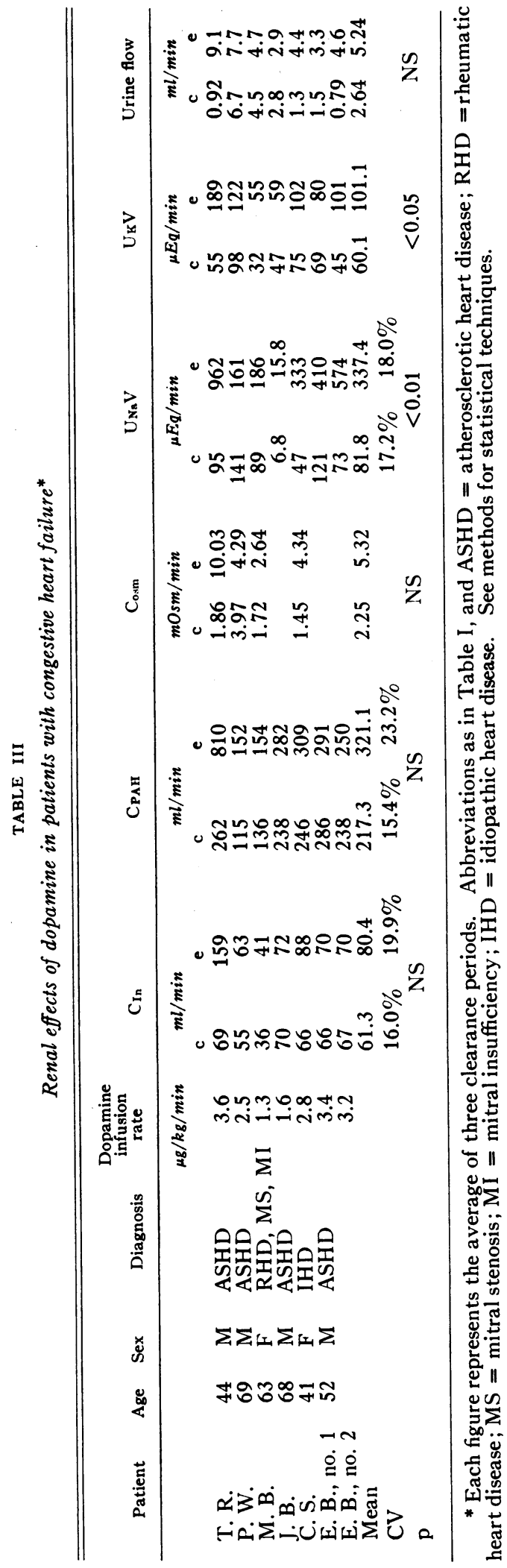

Effects of dopamine infusion in patients with congestive heart failure. Seven renal clearance and electrolyte excretion studies were performed on six patients (E. B. was studied on two occasions separated by a 10-day interval). These data are shown in Table III and Figure 4. A correction for body surface area was not made because of the presence of edema and ascites in some of the patients. Without exception, dopamine infusion was associated with an increase in mean GFR, ERPF, $\mathrm{C}_{\mathrm{osm}}, \mathrm{U}_{\mathrm{Na}} \mathrm{V}$, and $\mathrm{U}_{\mathrm{K}} \mathrm{V}$. However, only the increase in sodium excretion was significant. This reflects the large $\mathrm{CV}$ in this group of patients. The period-to-period variations in these patients are considerably larger than those obtained for the group of normal subjects. The variation was probably in part attributable to the low urine flow, but may also reflect less physiological stability in this group.

It is evident that urine volume increased most markedly in patients T. R. and E. B., no. 2 . These higher flows were nearly constant after 40 minutes' equilibration, and the changes in clearance and excretion were not attributable to washout effect.

Table IV summarizes the effects of dopamine on heart rate, mean arterial blood pressure, and pulse pressure in these studies. The responses to dopamine were quite variable and resembled the responses with the normal subjects in that no significant change in mean blood pressure or heart rate was observed. In contrast to the studies with the normal subjects, however, the pulse pressure was not significantly increased.

Side effects. Most of the subjects were aware of a more forceful beating of the heart during the dopamine infusions, but did not find this symptom distressing. Adverse effects were not observed during the dopamine infusions in which data were obtained. Typical angina pectoris, however, occurred in two patients (T.R. and J. B.) who were subject to angina on exertion, and an increased number of ventricular premature contractions occurred in a third patient (M. B.) at the time of initial infusions during which larger doses of dopamine were administered than were subsequently used during the renal clearance studies. These side effects were transitory and were relieved shortly after the dopamine infusions were 


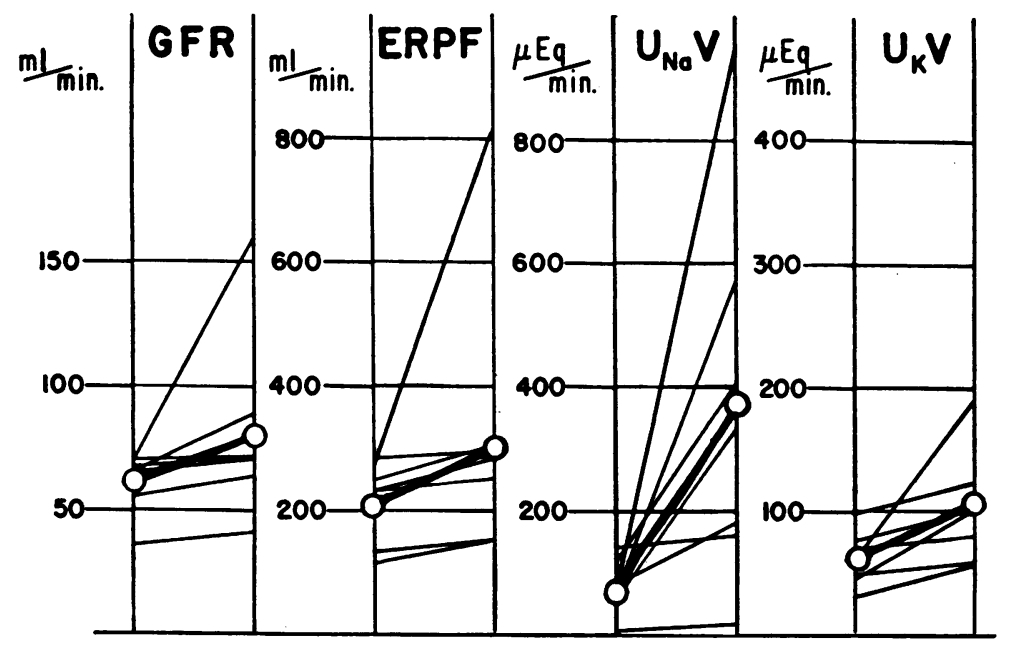

Fig. 4. EFFECTS OF DOPAMINE IN PATIENTS With CONGESTIVE heART FAILURE. Legend as in Figure 1, except that values are not corrected for BSA.

discontinued. These experiences indicate that dopamine, like other sympathomimetic amines, should be administered cautiously to patients with possible myocardial ischemia in order to avoid the consequences of excessive elevations of blood pressure and myocardial stimulation.

\section{Discussion}

The consistent increases in GFR, ERPF, and $\mathrm{U}_{\mathrm{Na}} \mathrm{V}$ produced by dopamine in normal subjects are in marked contrast to the effects previously found to occur in acute experiments with other sympathomimetic amines. The other naturally occurring catecholamines, epinephrine and norepinephrine, usually decrease ERPF and $\mathrm{U}_{\mathrm{Na}} \mathrm{V}$ when administered in doses that increase arterial pressure (20). When these catecholamines are administered in doses that produce minimal effects on blood pressure, ERPF frequently falls $(21,22)$.

Sympathomimetic amines, such as ephedrine and metaraminol, also differ from dopamine in their acute effects in normal subjects. These amines occasionally produce moderate increments in $\mathrm{U}_{\mathrm{Na}} \mathrm{V}$, but do not significantly change ERPF or GFR $(20,23-25)$. When these amines increased $\mathrm{U}_{\mathrm{Na}} \mathrm{V}$, they also increased mean arterial blood pressure. Accordingly, it is possible that the increments in sodium excretion were related to increased renal perfusion pressure (26). The natriuresis produced by dopamine cannot be explained by such a mechanism, since it occurred without significant changes in mean arterial pressure.

TABLE IV

Cardiovascular effects of dopamine in patients with congestive heart failure

\begin{tabular}{|c|c|c|c|c|c|c|c|}
\hline \multirow[t]{3}{*}{ Patient } & \multirow{2}{*}{$\begin{array}{c}\begin{array}{c}\text { Dopamine } \\
\text { infusion } \\
\text { rate }\end{array} \\
\mu g / \mathrm{kg} / \mathrm{min}\end{array}$} & \multicolumn{2}{|c|}{$\begin{array}{l}\text { Mean blood } \\
\text { pressure }\end{array}$} & \multicolumn{2}{|c|}{$\begin{array}{l}\text { Pulse } \\
\text { pressure }\end{array}$} & \multicolumn{2}{|c|}{$\begin{array}{l}\text { Heart } \\
\text { rate }\end{array}$} \\
\hline & & \multicolumn{2}{|c|}{$m m H g$} & \multicolumn{2}{|c|}{$m m \mathrm{Hg}$} & \multicolumn{2}{|c|}{ beats/min } \\
\hline & & c & e & c & $\mathrm{e}$ & c & e \\
\hline T. R. & 3.6 & 94 & 88 & 30 & 36 & 95 & 94 \\
\hline P. W. & 2.5 & 95 & 98 & 69 & 67 & 85 & 85 \\
\hline M. B. & 1.3 & 84 & 77 & 41 & 53 & 60 & 52 \\
\hline J. B. & 1.6 & 71 & 75 & 36 & 37 & 70 & 75 \\
\hline C. S. & 2.8 & 75 & 90 & 25 & 20 & 97 & 109 \\
\hline E. B., no. 1 & 3.4 & 74 & 88 & 28 & 51 & 83 & 95 \\
\hline E. B., no. 2 & 3.2 & 74 & 83 & 37 & 45 & 87 & 80 \\
\hline Mean & & 81 & 85 & 38 & 44 & 82 & 84 \\
\hline \multicolumn{2}{|l|}{ p } & \multicolumn{2}{|c|}{ NS } & \multicolumn{2}{|c|}{ NS } & \multicolumn{2}{|c|}{ NS } \\
\hline
\end{tabular}


Isoproterenol and mephentermine have in a few instances been observed to increase ERPF, GFR, and $\mathrm{U}_{\mathrm{Na}} \mathrm{V}$ in normal man (27). This and their effect in increasing cardiac output $(28,29)$ resemble the effects of dopamine, but in patients with congestive heart failure significant increase in $\mathrm{U}_{\mathrm{Na}} \mathrm{V}$ has not been observed. Sandler, Dodge, and Murdaugh (30) reported that the administration of isoproterenol to patients with congestive heart failure increased renal blood flow but did not increase sodium excretion significantly. The average increase in $\mathrm{U}_{\mathrm{Na}} \mathrm{V}$ produced by isoproterenol was $37 \%$ as compared to $365 \%$ in the patients infused with dopamine. The renal fraction of cardiac output decreased in most of the patients after isoproterenol administration, indicating that vascular beds other than the renal took a more active role in the vasodilatation produced by this amine. These results are in agreement with animal studies which indicate that the principal site of the vasodilatation produced by isoproterenol is the skeletal muscle (31). With regard to mephentermine, Frye, Kahler, and Braunwald (32) found that administration of this amine produced greater decompensation in three patients with cardiac insufficiency.

Of the agents that increase renal blood flow, the action of aminophylline is most like that of dopamine. In normal subjects (33-35) and in patients with congestive heart failure (35-37) aminophylline increases cardiac output, GFR, ERPF, and $\mathrm{U}_{\mathrm{Na}} \mathrm{V}$. Hydralazine increases cardiac output but, unlike dopamine, depresses arterial blood pressure and accelerates heart rate $(38,39)$. Hydralazine increases ERPF in normal subjects $(38,39)$, but its effect on GFR is uncertain (40, $41)$. The renal fraction of cardiac output is decreased by this agent (38). $\mathrm{U}_{\mathrm{Na}} \mathrm{V}$ is not reported to be increased in normal subjects by hydralazine (42), but a pronounced natriuresis occurs when this drug is administered to patients with hypertensive heart disease (38). The systemic hemodynamic effects of pyrogen are similar to those produced by aminophylline and dopamine (43). $\mathrm{U}_{\mathrm{Na}} \mathrm{V}$ and ERPF are increased in normal subjects, but GFR apparently does not increase $(43,44)$.

The regular increase in the filtered load of sodium produced by dopamine in these experiments is sufficient to account for the increased $\mathrm{U}_{\mathrm{Na}} \mathrm{V}$. Clearance techniques in this experimental design lack the sensitivity required to evaluate the possible contribution of simultaneous changes in tubular reabsorption of sodium. The increase of ERPF may account for the increase in GFR in these studies. The increase in ERPF without an increase of perfusion pressure denotes a fall in total intrarenal resistance. Such a decrease in resistance can result from vasodilatation, the opening of shunts, or a change in the effective viscosity of the blood.

Recent studies on the dog in our laboratories throw some additional light on the mechanism of action of dopamine in decreasing intrarenal resistance. Dopamine infusions increase ERPF, $\mathrm{GFR}$, and $\mathrm{U}_{\mathrm{Na}} \mathrm{V}$ in the same order of magnitude as seen in man (45). Administration of dopamine into the denervated renal artery of the dog, at doses not affecting systemic pressure, increases blood flow as measured by an electromagnetic flowmeter, indicating that the amine has a direct effect on renal resistance (46). This action cannot be blocked by dichloroisoproterenol, as are the effects of isoproterenol, and, therefore, the effect does not appear to be the result of combination with $\beta$-adrenergic receptors (47). Other studies in the dog have shown that dopamine produces reflex reduction of resistance in the perfused limb (5). Accordingly, it is possible that the decreased renal resistance observed in man may be the result of both direct and reflex actions of dopamine. In the dog dopamine infusions decrease renal extraction of PAH (48), a finding consistent with the possibility of a change in the intrarenal distribution of renal blood flow.

Dopamine's reduction of renal resistance in man suggests that this naturally occurring catecholamine may have a physiologic role in the regulation of renal blood flow. Speculations concerning a possible physiologic role for dopamine have been made by other investigators. Holtz (49) found high concentrations of dopamine in the intestine and lung and suggested that the amine may act as a nonneuronal transmittor substance. Carlsson (50) reported that there was a higher concentration of dopamine than norepinephrine in the corpus striatum and postulated that the amine may be involved in extrapyramidal function. More recently, Allwood, Cobbold, and Ginsburg (51) found that injection of dopamine into the brachial artery produced piloerection. Since a 
similar effect did not occur with epinephrine or norepinephrine, they suggested that dopamine may be involved in normal piloerector responses. The similar effects of dopamine on the ERPF, GFR, and $\mathrm{U}_{\mathrm{Na}} \mathrm{V}$ in normal man and patients in heart failure suggest that the mechanisms are the same in both states. The consistency of the response in heart failure is indicated by the increased $\mathrm{U}_{\mathrm{Na}} \mathrm{V}$ observed in each of 12 patients to whom dopamine has now been administered (52).

\section{Summary}

1) Dopamine, the biochemical precursor of norepinephrine, was infused intravenously into nine normal subjects and six patients with congestive heart failure.

2) Sodium excretion increased significantly in both normal subjects and patients with congestive heart failure.

3) Glomerular filtration rate and renal plasma flow also increased in normal subjects.

4) Hemodynamic studies in five normal subjects indicated that dopamine increased cardiac output and decreased peripheral resistance. The renal fraction of cardiac output did not change significantly.

5) These studies have shown that the renal effects of dopamine are different from those reported for other sympathomimetic amines.

\section{Acknowledgments}

We thank Miss Bettye Saylor, Dr. E. Garland Herndon, Director, Clinical Research Facility, Emory University, and Dr. Carl Pirkle, Director, U. S. Public Health Service Hospital, Atlanta Federal Penitentiary, for assisting us in these studies. Consultation concerning statistical methods and interpretation was kindly provided by Dr. Malcolm Turner, Professor of Biometry, Emory University School of Medicine.

\section{References}

1. Blaschko, H. The development of current concepts of catecholamine formation. Pharmacol. Rev. 1959, 11, 307.

2. Barger, G., and H. H. Dale. Chemical structure and sympathomimetic action of amines. J. Physiol. (Lond.) 1910, 41, 19.

3. Holtz, P., and K. Credner. Die enzymatische Entstehung von Oxytyramin in Organismus und die physiologische Bedeutung der Dopadecarboxylase. Naunyn-Schmiedeberg's Arch. exp. Path. Pharmak. 1942, 200, 356.

4. Burn, J. H., and M. J. Rand. The depressor action of dopamine and adrenaline. Brit. J. Pharmacol. 1958, 13, 471.

5. McDonald, R. H., Jr., and L. I. Goldberg. Analysis of the cardiovascular effects of dopamine in the dog. J. Pharmacol. exp. Ther. 1963, 140, 60.

6. Horwitz, D., S. M. Fox III, and L. I. Goldberg. Effects of dopamine in man. Circulat. Res. 1962, 10, 237.

7. Mueller, P. S., and D. Horwitz. Plasma free fatty acid and blood glucose responses to analogues of norepinephrine in man. J. Lipid Res. 1962, 3, 251.

8. Bogdonoff, M. D., J. W. Linhart, R. J. Klein, and E. H. Estes, Jr. The specific structure of compounds effecting fat mobilization in man. J. clin. Invest. 1961, 40, 1993.

9. Horwitz, D., L. I. Goldberg, and A. Sjoerdsma. Increased blood pressure responses to dopamine and norepinephrine produced by monoamine oxidase inhibitors in man. J. Lab. clin. Med. 1960, 56, 747.

10. Goldenberg, M., K. L. Pines, E. de F. Baldwin, D. G. Greene, and C. E. Roh. The hemodynamic response of man to norepinephrine and epinephrine and its relation to the problem of hypertension. Amer. J. Med. 1948, 5, 792.

11. Goldberg, L. I., R. H. McDonald, Jr., and A. M. Zimmerman. Sodium diuresis produced by dopamine in patients with congestive heart failure. New Engl. J. Med. 1963, 269, 1060.

12. Roe, J. H., J. H. Epstein, and N. P. Goldstein. A photometric method for the determination of inulin in plasma and urine. J. biol. Chem. 1949, 178, 839.

13. Smith, H. W., N. Finkelstein, L. Aliminosa, B. Crawford, and M. Graber. The renal clearances of substituted hippuric acid derivatives and other aromatic acids in dog and man. $\mathrm{J}$. clin. Invest. 1945, 24, 388.

14. Lenkei, S. C., S. M. Fox III, and T. N. Lynn. Accurate technic for the volumetric calibration of dye-dilution curves. Circulation 1959, 20, 727.

15. Hamilton, W. F., J. W. Moore, J. M. Kinsman, and R. G. Spurling. Studies on the circulation: IV. Further analyses of the injection method, and of changes in hemodynamics under physiological and pathological conditions. Amer. J. Physiol. 1932, 99, 534.

16. Snedecor, G. W. Statistical Methods, 5th ed. Ames, Iowa, Iowa State University Press, 1956, p. 49.

17. Bartlett, M. S. The use of transformations. Biometrics 1947, 3, 39.

18. Snedecor, G. W. Statistical Methods, 5th ed. Ames, Iowa, Iowa State University Press, 1956, p. 62.

19. Davies, D. F., and M. W. Shock. The variability of measurement of inulin and Diodrast tests of kidney function. J. clin. Invest. 1950, 29, 491.

20. Nickel, J. F., C. McC. Smythe, E. M. Papper, and S. E. Bradley. A study of the mode of action of the adrenal medullary hormones on sodium, potassium and water excretion in man. J. clin. Invest. 1954, 33, 1687. 
21. Pullman, T. N., and W. W. McClure. The response of the renal circulation of man to constant-speed infusions of 1-norepinephrine. Circulation 1954, 9, 600.

22. Pullman, T. N., and W. W. McClure. The effect of 1-noradrenaline on electrolyte excretion in normal man. J. Lab. clin. Med. 1952, 39, 711.

23. Maxwell, M. H., P. Morales, and C. H. Crowder, Jr. Effect of therapeutic doses of ephedrine on renal clearances in normal man. Proc. Soc. exp. Biol. (N. Y.) 1951, 77, 539.

24. Gornel, D. L., R. G. Lancestremere, S. Papper, and L. M. Lowenstein. Acute changes in renal excretion of water and solute in patients with Laennec's cirrhosis, induced by the administration of the pressor amine, metaraminol. J. clin. Invest. 1962, 41, 594.

25. Livesay, W. R., J. H. Moyer, and D. W. Chapman. The cardiovascular and renal hemodynamic effects of Aramine. Amer. Heart J. 1954, 47, 745.

26. Kruhøffer, P. Handling of alkali metal ions by the kidney in Handbuch der Experimentellen Pharmakologie, O. Eichler and A. Farah, Eds. Berlin, Springer, 1960, vol. 13, p. 271.

27. Tuttle, E. P. Saluresis from drug-induced hypertension. Clin. Res. 1960, 8, 234.

28. Li, T-H., S. Shimosato, and B. Etsten. Hemodynamics of mephentermine in man. New Engl. J. Med. 1962, 267, 180.

29. Dodge, H. T., J. D. Lord, and H. Sandler. Cardiovascular effects of isoproterenol in normal subjects and subjects with congestive heart failure. Amer. Heart J. 1960, 60, 94.

30. Sandler, H., H. T. Dodge, and H. V. Murdaugh, Jr. Effects of isoproterenol on cardiac output and renal function in congestive heart failure. Amer. Heart J. 1961, 62, 643.

31. Ahlquist, R. P. A study of the adrenotropic receptors. Amer. J. Physiol. 1948, 153, 586.

32. Frye, R. L., R. L. Kahler, and E. Braunwald. The ineffectiveness of an inotropic agent, mephentermine (Wyamine) in the treatment of congestive heart failure. Amer. Heart J. 1961, 62, 301.

33. Escher, D. J. W., R. E. Weston, G. Leiner, L. Leiter, and S. Goldat. The effect of aminophylline on cardiac output and renal hemodynamics in man. Fed. Proc. 1948, 7, 31.

34. Howarth, S., J. McMichael, and E. P. SharpeySchafer. The circulatory action of theophylline ethylene diamine. Clin. Sci. 1946, 6, 127.

35. Davis, J. O., and N. W. Shock. The effect of theophylline ethylene diamine on renal function in control subjects and in patients with congestive heart failure. J. clin. Invest. 1949, 28, 1459.

36. Fowell, D. M., J. A. Winslow, V. P. Sydenstricker, and N. C. Wheeler. Circulatory and diuretic effects of theophylline isopropanolamine. Arch. intern. Med. 1949, 83, 150.

37. Sinclair-Smith, B., A. A. Kattus, J. Genest, and E. V. Newman. The renal mechanism of elec- trolyte excretion and the metabolic balances of electrolytes and nitrogen in congestive cardiac failure. The effects of exercise, rest and aminophylline. Bull. Johns Hopk. Hosp. 1949, 84, 369.

38. Wilkinson, E. L., H. Bachman, and H. H. Hecht. Cardiovascular and renal adjustments to a hypotensive agent. J. clin. Invest. 1952, 31, 872.

39. Freis, E. D., and F. A. Finnerty, Jr. Suppression of vasomotor reflexes in man following 1-hydrazinophthalazine (C-5968). Proc. Soc. exp. Biol. (N. Y.) 1950, 75, 23.

40. Reubi, F. C. Renal hyperemia induced in man by a new phthalazine derivative. Proc. Soc. exp. Biol. (N. Y.) 1950, 73, 102.

41. Moyer, J. H., C. A. Handley, and R. A. Huggins. Some pharmacodynamic effects of 1-hydrazinophthalazine (C-5968) with particular reference to renal function and cardiovascular response. $\mathrm{J}$. Pharmacol. exp. Ther. 1951, 103, 368.

42. Judson, W. E., W. Hollander, I. H. Friedman, J. D. Hatcher, and M. H. Halperin. Studies on congestive failure: the effects of exercise, salt loading and of intravenous Apresoline on cardiorenal hemodynamics and the excretion of sodium and water (abstract). J. clin. Invest. 1953, 32, 579.

43. Bradley, S. E., H. Chasis, W. Goldring, and H. W. Smith. Hemodynamic alterations in normotensive and hypertensive subjects during the pyrogenic reaction. J. clin. Invest. 1945, 24, 749.

44. Latham, W. Urinary excretion of sodium and potassium during the pyrogenic reaction (abstract). J. clin. Invest. 1954, 33, 951.

45. McNay, J. L., R. H. McDonald, Jr., and L. I. Goldberg. Natriuretic effect of dopamine infusion in the dog. Fed. Proc. 1963, 22, 662.

46. McNay, J. L., R. H. McDonald, Jr., and L. I. Goldberg. Direct renal vasodilation produced by dopamine in the dog. Clin. Res. 1963, 11, 248.

47. McNay, J. L., R. H. McDonald, Jr., and L. I. Goldberg. Comparative effects of dopamine on renal and femoral blood flows (abstract). Pharmacologist 1963, 5, 269.

48. McNay, J. L. Unpublished data.

49. Holtz, P. Role of 1-dopa decarboxylase in the biosynthesis of catecholamines in nervous tissue and the adrenal medulla. Pharmacol. Rev. 1959, 11, 317.

50. Carlsson, A. The occurrence, distribution and physiological role of catecholamines in the nervous system. Pharmacol. Rev. 1959, 11, 490.

51. Allwood, M. J., A. F. Cobbold, and J. Ginsburg. Peripheral vascular effects of noradrenaline, isopropylnoradrenaline, and dopamine. Brit. med. Bull. 1963, 19, 132.

52. Zimmerman, A. M., R. H. McDonald, Jr., J. L. McNay, and L. I. Goldberg. Increased sodium excretion produced by dopamine in patients with congestive heart failure (abstract). Circulation $1963,28,828$. 